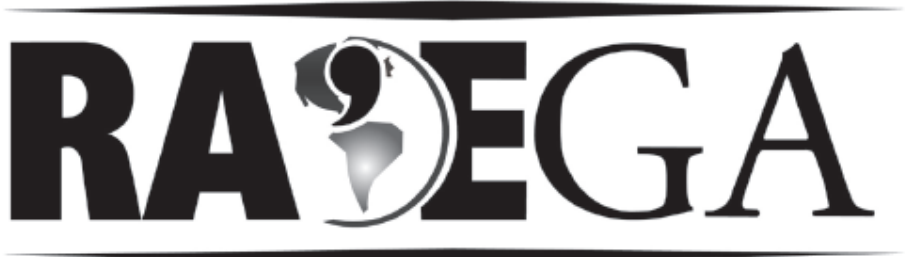

O ESPAÇO GEOGRÁFICO EM ANÁLISE

\title{
CONSIDERAÇÕES SOBRE A DESCONSTRUÇÃO DO LICENCIAMENTO AMBIENTAL BRASILEIRO
}

\section{CONSIDERATIONS ABOUT THE DESCONSTRUCTION OF BRAZILIAN ENVIRONMENTAL LICENSING}

\author{
Alexandre Cosme José Jeronymo ${ }^{1}$ \\ Célio Bermann ${ }^{2}$ \\ Sinclair Mallet Guy Guerra ${ }^{3}$
}

\begin{abstract}
Resumo
Este trabalho contribui para ampliar o debate entre os órgãos ambientais que analisam projetos hidrelétricos para concessão de licenças ambientais e os agentes econômicos interessados nas licenças. São apresentadas informações empíricas sobre a infraestrutura viária identificada na Área de Influência Direta (AID) do projeto UHE Tijuco Alto e contrastadas com as informações sobre a infraestrutura viária do Estudo de Impacto Ambiental (EIA) do projeto. Foi constado que o volume de informações empíricas catalogadas na AID é superior ao do EIA. O contraste indica que o EIA merece análise criteriosa,
\end{abstract}

\footnotetext{
${ }^{1}$ Graduado em Ciências Sociais (UNESP, 2001), Mestrado em Energia (USP, 2007), Doutorado em Energia (UFABC, 2012). É Pesquisador do Instituto Brasileiro de Estudos Contemporâneos (IBEC). São Paulo/SP, Brasil. Correio eletrônico: <alexandrecij@gmail.com>.

${ }^{2}$ Graduado em Arquitetura e Urbanismo (USP, 1975), Mestrado em Planejamento Urbano e Regional (UFRJ, 1978), Doutorado em Planejamento de Sistemas Energéticos (UNICAMP, 1991), Pós Doutorado (USP, 1991), Livre Docência (USP, 2006). É Professor do Instituto de Eletrotécnica e Energia (IEE) da Universidade de São Paulo. São Paulo/SP, Brasil. Correio eletrônico: <cbermann@iee.usp.br>.

${ }_{3}$ Graduado em Economia (Universidade de Marilia, 1966), Mestrado em Economia (FGV, 1981), Doutorado em Economia da Energia (Université Sourbonne Nuvelle - Paris 3, 1986), Pós Doutorado (Université Laval, 1993), Livre Docência (UNICAMP, 2004). É Professor Visitante Nacional Sênior (PVNS) pela Universidade Federal do ABC (UFABC). Santo André/SP, Brasil. Correio eletrônico: <sguerra@ufabc.edu.br>.
} 
aprofundada e interdisciplinar, e as lacunas contribuem para ampliar o período dedicado para análise do EIA e obstruem avaliações futuras.

Palavras chave: Infraestrutura viária; Estudo de Impacto Ambiental; Usina Hidrelétrica de Energia.

\begin{abstract}
This work contributes to extend the discussion between the environmental agencies who analyze hidroelectric projects for environmental licensing, and the interested economic agents in the licenses. Information empirical on the identified road infrastructure in the Area of Direct Influence of project HP Tijuco Alto are presented and contrasted with the information on the road infrastructure of the study of ambient impact (EIA) of the project. The volume of empirical information is greater to the one of the EIA. The contrast indicates that the EIA deserves careful analysis, deepened and interdisciplinary gaps and contribute to increasing the time dedicated to analysis of EIA and obstructs future evaluations.
\end{abstract}

Key words: Road infrastructure; environmental impact study; hydroelectric power.

\title{
Introdução
}

O marco da Política Nacional de Meio Ambiente (PNMA) está inserido na transição do regime político ditadorial (1964 - 1985) para a democracia brasileira. Neste período, os canais de participação social sobre o tema meio ambiente, bem como a implementação de mecanismos regulatórios ambientais foram expandidos.

A lei $\mathrm{n}^{\circ}$ 6.803/1980 "dispõe sobre as diretrizes básicas para 0 zoneamento industrial nas áreas críticas de poluição, e dá outras providências" (BRASIL, 1980), e prevê a realização de Estudo de Impacto Ambiental (EIA) para atividades industriais inclusas nas áreas de elevada poluição. Essa lei, segundo Machado (1988) é o resultado de emenda apresentada aos parlamentares pela Sociedade Brasileira de Direto do Meio Ambiente.

\footnotetext{
Essa lei chegou atrasada no concernente à degradação ambiental nas cidades de Cubatão/SP, São Paulo/SP, Santo André/SP, São Bernardo do Campo/SP e Diadema/SP, mas não deixou de fazer concretas exigências quanto à obrigatoriedade do EIA para aprovação de zonas de uso estritamente industriais destinadas à localização de pólos
} 
petroquímicos, cloroquímicos, bem como instalações nucleares (MACHADO, 1988: 77).

O EIA é uma avaliação preventiva e de monitoramento dos danos ambientais. A evolução da legislação ambiental brasileira continua com a "lei no 6.938/1981 que dispõe sobre a Política Nacional de Meio Ambiente (PNMA), seus fins e mecanismos de formulação e aplicação (BRASIL, 1981) e, o seu art. 9ㅜ, tece consideração sobre os mecanismos necessários para a aplicação e regulamentação da legislação. O licenciamento ambiental, portanto, é um dos mecanismos identificados para aplicação e regulamentação da legislação ambiental, conforme a resolução do Conselho Nacional de Meio Ambiente (CONAMA).

\footnotetext{
Licenciamento ambiental: procedimento administrativo pelo qual o órgão ambiental competente licencia a localização, instalação, ampliação e operação de empreendimento e atividades utilizadoras de recursos ambientais considerados de efetiva ou potencialmente poluidoras ou daquelas que, sob qualquer forma, possam causar degradação ambiental, considerando as disposições legais e regulamentares e as normas técnicas (BRASIL, 1997).
}

A elaboração do marco legal para a PNMA esteve associada à identificação dos órgãos ambientais responsáveis pela fiscalização das práticas e usos dos recursos. Segundo Brasil (1998) é competência comum da União, dos Estados, do Distrito Federal e dos Municípios, a proteção ao meio ambiente, o combate a poluição em qualquer de suas formas e a preservação das florestas, da fauna e da flora. Porém, no âmbito do licenciamento ambiental de empreendimentos que impactem dois ou mais estados ou ultrapassem os limites territoriais do país, essa competência é de responsabilidade do Instituto Brasileiro de Meio Ambiente e Recursos Renováveis (IBAMA), órgão do governo federal responsável pela execução da PNMA, e para os empreendimentos com impactos estaduais os licenciamentos são responsabilidades dos órgãos estaduais.

Segundo Brasil (1986) a resolução do CONAMA n 1 define que as Usinas Hidrelétricas de Energia (UHE) estão sujeitas ao licenciamento 
ambiental. O procedimento para obter 0 licenciamento de UHE requer a apresentação de EIA ao órgão ambiental competente. O licenciamento ambiental, por sua vez, é composto pelas etapas da licença prévia, licença de instalação e licença de operação, apresentadas a seguir pela resolução CONAMA no 237/1997.

\begin{abstract}
I - Licença Prévia (LP) - concedida na fase preliminar do planejamento do empreendimento ou atividade aprovando sua localização e concepção, atestando a viabilidade ambiental e estabelecendo os requisitos básicos e condicionantes a serem atendidos nas próximas fases de sua implementação; II - Licença de Instalação (LI) - autoriza a instalação do empreendimento ou atividade de acordo com as especificações constantes dos planos, programas e projetos aprovados, incluindo as medidas de controle ambiental e demais condicionantes, da qual constituem motivo determinante; III - Licença de Operação (LO) - autoriza a operação da atividade ou empreendimento, após a verificação do efetivo cumprimento do que consta das licenças anteriores, com as medidas de controle ambiental e condicionantes determinados para a operação (BRASIL, 1997).
\end{abstract}

A elaboração, a construção e a institucionalização do licenciamento ambiental são instrumentos para prevenção e reparação das diferentes ordens de impactos (sociais, econômicos, ambientais, culturais, entre outros) e magnitudes, bem como controlar a utilização do recurso natural. Entretanto, a evolução do licenciamento ambiental, para alguns setores da economia, desponta como instrumento com problemas de encaminhamento.

Segundo Lima e Magrini (2009) os grandes conflitos têm ocorrido no licenciamento ambiental para construção de UHE, na infraestrutura de estradas e portos. Veiga e Pombo (2008) apontam que a Indústria Brasileira de Energia Elétrica $^{4}$ (IBEE) classifica o licenciamento ambiental como um entrave para o desenvolvimento do país.

Pesquisa desenvolvida pelo Banco Mundial (2008: 9) indica que, por um lado, as regras do licenciamento ambiental mantêm-se inalteradas desde as suas origens, e os órgãos ambientais não apresentam significativo aumento de capacidade institucional e, por outro lado, existe a argumentação de que a

\footnotetext{
${ }^{4}$ A Indústria Brasileira de Energia Elétrica (IBEE) tem em sua composição empresas públicas e privadas. São empresas de geração, transmissão e distribuição de eletricidade.
} 
IBEE produziu importantes modificações em suas ações nos últimos 10 anos. Para Godoy (2009) a legislação ambiental está estática.

\footnotetext{
Há muitos exemplos de legislações repletas de anacronismos, mesmo que tenham sido escritas com justas intenções, como a tributária, a trabalhista, a ambiental e a de licitações públicas. Criou-se no Brasil uma estrutura gigantesca para precaver contra todos os perigos, mas que, na prática, tem servido para visões de mundos particulares daqueles que fazem essa máquina funcionar, ignorando os anseios e as necessidades da sociedade. É preciso abrir o debate, preservar as conquistas e corrigir os desvios (GODOY, 2009).
}

Análises que questionam a reduzida capacidade institucional dos órgãos ambientais, de modo geral, estão apoiadas na lentidão para analisar cada processo, e podem destacar o licenciamento ambiental como instrumento que se interpõe aos propósitos da IBEE em gerar, transmitir e distribuir energia elétrica. Além disso, o questionamento da capacidade institucional dos órgãos ambientais encontra parcela dos seus fundamentos nas pressões recebidas pelos próprios órgãos. Segundo Zhouri, Laschesfiki e Paiva (2005) a legislação tem sido reinterpretada, casuisticamente, em especial quando entendida como obstáculo ou quando se apresenta contrária ao modelo de desenvolvimento e aos interesses vorazes do mercado.

Considerações do governo brasileiro (BRASIL, 2008: 8) recomendam a necessária e correta contextualização do licenciamento ambiental no conjunto das condições estruturais e conjunturais que 0 apontam como um dos problemas para o desenvolvimento da IBEE, e as abordagens que desqualificam os instrumentos da PNMA podem conter vieses correlacionados aos interesses econômicos, destituindo, então, os aspectos que envolvem as atividades antrópicas e as questões ambientais. Neste sentido, a construção de um marco legal ambiental e a sua efetiva execução se interpõe aos EIAs com informações incompletas. Por conseguinte, tais estudos incompletos podem significar que a PNMA dificilmente será cumprida integralmente.

Um EIA deficiente pode subtrair atividades antrópicas, infraestruturas sociais e econômicas, espécies animais e vegetais. A subtração poderá acontecer a partir das falhas involuntárias, erros que podem ocorrer ao longo 
do processo de elaboração do EIA, mas não será anulada a possibilidade que é a subtração premeditada, previamente determinada. No segundo caso, a premeditação, o seu significado pode ser concebido a partir da reflexão sobre a invisibilização. Segundo Leroy (2003: 9) a invisibilização corresponde ao descaso do governo, dos bancos multilaterais, das empresas construtoras e dos consultores que elaboram EIA. A invisibilização, portanto, é o produto dos pareceres determinados, pré-noções e conceitos previamente estabelecidos.

O processo de invisibilização das atividades antrópicas, da vida animal e vegetal, é fundamentado, no propósito em estabelecer distanciamento com o outro, desconsiderando-o. Nessa posição não será desconsiderada, inclusive, a estruturação do processo de anulação do diferente, do contrário, do outro. Mas por outro lado, a invisibilização, é certo, está entrelaçada com os mecanismos que preveem redução dos custos para instalação dos empreendimentos. Essas considerações são desenvolvidas a seguir.

- Invisibilizar como mecanismo para promover anulação das atividades sociais pré-existentes no espaço designado para construção do empreendimento. Invisibilizar a imaterialidade da presença de organização (social, política, cultural, econômica) e desconsiderar a existência de sujeitos portadores de conhecimentos e direitos. O processo de invisibilização anula as relações imateriais, por exemplo, como os laços de sociabilidade rompidos pelo deslocamento involuntário no ato da apropriação de propriedades para construção de UHE, os costumes, o parentesco, a religião, a cultura, a organização social.

- Invisibilizar como mecanismo para reduzir custos com o empreendimento, afinal, somente será considerado como compensação e, portanto, a ser restituído pelo agente econômico, o que estiver identificado no EIA. Aqui se encontram as perdas materiais invisibilizadas, por exemplo, os bens familiares e comunitários, como a infraestrutura física (residência, estrada, poste, saneamento, culturas agrícolas, pontes).

Com o propósito em analisar as informações sobre infraestrutura viária contida no EIA do projeto UHE Tijuco Alto, foi desenvolvido levantamento de informações empíricas na Área de Influência Direta (AID) do projeto. Através da 
coleta de dados primários foi identificada diferença substancial entre a quantidade de infraestrutura viária encontrada na AID e a mencionada no EIA. Tal fato questiona as críticas da IBEE com relação à incapacidade dos órgãos responsáveis pelas análises dos licenciamentos ambientais em analisar, e revela que os EIAs incompletos demandam maior tempo para análise dos órgãos responsáveis.

\section{A Companhia Brasileira de Alumínio e o Projeto usina Hidrelétrica de Energia (UHE) Tijuco Alto}

O Grupo Votorantin é um dos conglomerados brasileiros atuando nos ramos industriais e financeiros. Uma das empresas do grupo é a Companhia Brasileira de Alumínio (CBA), inaugurada em 1935. A produção industrial da CBA consiste em produtos fundidos (bobinas, lingotes, placas, tarugos, vergalhões) e produtos transformados (cabos, placas, exdrudados, folhas de alumínio, vergalhões).

Segundo a Associação Brasileira de Alumínio - ABAL (2011) o insumo básico para a produção do alumínio primário é a eletricidade, e o consumo de 15 mega watt hora (MWh) produz o equivalente a 1 tonelada de alumínio. A particularidade eletrointensiva (grande consumidora de eletricidade por cada unidade produzida) deste setor industrial tem sido objeto de apreciação do poder público. Segundo Brasil (1996) o decreto n॰2003/1996, regulamenta a produção de energia elétrica por produtor independente e auto-produtor, a partir da concessão ou autorização para produzir energia elétrica destinada ao seu uso exclusivo.

Para manter o crescimento (CBA, 2011a) médio anual de 10\%, a CBA produz cerca de $60 \%$ da eletricidade requerida para manutenção da produção industrial. Segundo a ANEEL (2011a, 2011b) e a CBA (2011b), a produção de eletricidade destinada para o consumo industrial da própria CBA, a partir das usinas hidrelétricas próprias e consorciadas, equivale a 1.269.790 quilowatt $(\mathrm{KW})$. 
A tabela 1, a seguir, apresenta as potências outorgadas das usinas hidrelétricas, próprias e consorciadas da CBA.

Tabela 1. Procedência da eletricidade para abastecer a Companhia Brasileira de Alumínio

\begin{tabular}{|c|c|c|c|c|}
\hline$=$ & $\begin{array}{c}\text { Fornecedores de } \\
\text { eletricidade para CBA }\end{array}$ & Rio / Estado & $\begin{array}{c}\text { Potência } \\
\text { outorgada } \\
(\mathbf{K w})^{\mathrm{a}}\end{array}$ & $\begin{array}{c}\text { Propriedade } \\
\text { da CBA }\end{array}$ \\
\hline 1 & UHE Alecrim & Juquiá - Guaçú/SP & 72.000 & $72.000^{\mathrm{b}}$ \\
\hline 2 & UHE Barra & Juquiá - Guaçú/SP & 40.400 & $40.400^{\mathrm{b}}$ \\
\hline 3 & UHE Canoas 1 & Paranapanema/SP & 82.500 & $41.490^{\mathrm{C}}$ \\
\hline 4 & UHE Canoas 2 & Paranapanema/SP & 72.000 & $36.210^{\mathrm{C}}$ \\
\hline 5 & PCH França & Juquiá - Guaçú/SP & 29.500 & $29.500^{\mathrm{b}}$ \\
\hline 6 & UHE Fumaça & Juquiá - Guaçú/SP & 36.400 & $36.400^{\mathrm{b}}$ \\
\hline 7 & UHE Itupararanga & Sorocaba/SP & 55.000 & $55.000^{\mathrm{b}}$ \\
\hline 8 & PCH Jurupará & Peixe/SP & 7.200 & $7.200^{\mathrm{b}}$ \\
\hline 9 & UHE Ourinhos & Paranapanema/SP & 44.000 & $44.000^{\mathrm{b}}$ \\
\hline 10 & UHE Piraju & Paranapanema/SP & 70.000 & $70.000^{\mathrm{b}}$ \\
\hline 11 & PCH Porto Raso & Paranapanema/SP & 28.400 & $28.400^{\mathrm{b}}$ \\
\hline 12 & UHE Salto do Iporanga & Assungui/SP & 36.870 & $36.870^{\mathrm{b}}$ \\
\hline 13 & PCH Serraria & Juquiá - Guaçú/SP & 24.000 & $24.000^{\mathrm{b}}$ \\
\hline 14 & UHE Barra Grande & Pelotas/ RS - SC & 690.000 & $103.500^{\mathrm{d}}$ \\
\hline 15 & UHE Campos Novos & Canoas/SC & 880.000 & $217.588^{\mathrm{e}}$ \\
\hline 16 & UHE Machadinho & Pelotas/SC & 1.140 .000 & $312.588^{\mathrm{f}}$ \\
\hline 17 & PCH Santa Helena & Sorocaba/SP & 2.240 & $2.240^{\mathrm{b}}$ \\
\hline 18 & PCH Votorantim & Sorocaba/SP & 3.000 & $3.000^{\mathrm{b}}$ \\
\hline 19 & UHE Salto do Pilão & Itajaí/SC & 182.340 & $109.404^{\mathrm{g}}$ \\
\hline$==$ & TOTAL & $==$ & 3.495 .850 & 1.269 .790 \\
\hline
\end{tabular}

Fonte: Tabela elaborada pelo autor.

UHE = Usina Hidrelétrica de Energia. $\mathrm{PCH}=$ Pequena Central Hidrelétrica.

a Ver: ANEEL (2011a; 2011b).

b Produção hidrelétrica destinada integralmente para CBA. Ver: ANEEL (2011a; 2011b), CBA (2011b).

${ }^{c}$ CBA é proprietária de 50,3\% da geração. Ver: ANEEL (2011a; 2011b).

d CBA é proprietária de $15 \%$ da geração. Ver: CBA (2011b).

e CBA é proprietária de $24,726 \%$ da geração. Ver: ENERCAN (2011).

${ }^{\dagger}$ CBA é proprietária de 27,42\% da geração. Ver: ANEEL (2011a; 2011b).

${ }^{9}$ CBA é proprietária de $60 \%$ da geração. Ver: ANEEL (2011a; 2011b), Consórcio Empresarial Salto do Pilão (2011).

\section{O projeto Usina Hidrelétrica de Tijuco Alto}

O projeto UHE de Tijuco Alto foi concebido para construção na Bacia Hidrográfica do rio Ribeira de Iguape, na divisa interestadual do rio Ribeira de Iguape, entre os estados de São Paulo e Paraná, na região do Vale do Ribeira. 
O rio Ribeira de Iguape possui a extensão de $470 \mathrm{~km}$, sendo $340 \mathrm{~km}$ paulista, $120 \mathrm{~km}$ paranaense e $90 \mathrm{~km}$ de divisa interestadual.

O Vale do Ribeira destaca-se pela preservação do bioma da Mata Atlântica, restingas e mangues. A região possui parques ambientais, cavernas, sítios arqueológicos e paleontológicos, e uma das regiões lagunares mais preservadas do planeta. A UNESCO - Organização das Nações Unidas para Ciência, a Educação e a Cultura (ISA, 2001) conferiu aos municípios do Vale do Ribeira o diploma de Patrimônio Natural da Humanidade. Segundo o ISA (2001) para ser considerado patrimônio natural é necessário apresentar riqueza em biodiversidade, ótimo estado de conservação da configuração original da área e valor estético singular.

A formação social, cultural, ambiental do Vale do Ribeira é diversificada por conta da presença dos povos tradicionais quilombolas, indígenas e caiçaras. Os modos de vida dessas populações caracterizam-se pela interação com a natureza, a partir da apropriação de recursos naturais que satisfaçam as subsistências familiar e comunitária. Neste sentido, as relações dessas sociedades com a natureza prima pelo baixo impacto ambiental. A singularidade ambiental do Vale do Ribeira e a sua diversidade sociocultural, contrastam com a própria realidade de representar uma das regiões mais pobres dos estados de São Paulo e do Paraná. Os municípios do Vale do Ribeira são portadores de reduzidos Índices de Desenvolvimento Humano (IDH) e de infraestrutura produtiva. Não é incomum a ocorrência de migrações do Vale do Ribeira para outras regiões por conta das insuficientes oportunidades de empregos e de estudos que a região oferece.

Conforme CBA \& CNEC (2005) dentre os elementos que contribuem para inibir o desenvolvimento regional no Vale do Ribeira está o próprio relevo.

A Área de Influência da UHE de Tijuco Alto ficou às margens dos processos de desenvolvimento dos estados de São Paulo e Paraná, principalmente em função do relevo acidentado e sua inserção em Mata Atlântica, que contribuem para o pequeno desenvolvimento regional e a estagnação das atividades produtivas (CBA \& CNEC, 2005). 
Defender que o relevo regional é o responsável pela marginalização do processo de desenvolvimento de uma dada região permite afastar o tema que é a tímida presença do estado, ao longo de décadas, no Vale do Ribeira. Elementos tributários dos reduzidos processos de desenvolvimento e a pobreza regional, de modo geral, estão relacionados aos precários incentivos para fomentar a infraestrutura social (escolas, serviços de saúde, iluminações pública e residencial, etc.) e os reduzidos investimentos na infraestrutura econômica (transporte, telecomunicações, água e saneamento básico, etc.) associados às particularidades regionais (no caso do Vale do Ribeira, por exemplo, o patrimônio natural que é a Mata Atlântica).

A CBA é o agente econômico responsável pelo projeto UHE Tijuco Alto. $O$ propósito da CBA é consumir a eletricidade gerada pela usina em sua planta industrial em Alumínio, SP (CBA \& CNEC, 2005c: 16). Desde 1989 a CBA tenta receber a aprovação do licenciamento do projeto UHE Tijuco Alto.

Em 1989 a CBA protocolou documentos na Secretaria de Meio Ambiente (SMA) do Estado de São Paulo e na Superintendência dos Recursos Hídricos e do Meio Ambiente (SUREHMA) do Estado do Paraná, pleiteando licenças ambientais para o projeto UHE Tijuco Alto. As licenças prévias foram concedidas em 14/06/1994 pelo Conselho Estadual de Meio Ambiente/Secretaria Estadual do Meio Ambiente de São Paulo e em 22/02/1995 pelo Instituto Ambiental do Paraná (IAP). O licenciamento foi indeferido por meio de ação civil pública, amparada por uma mobilização envolvendo parlamentares, entidades ambientalistas, lideranças comunitárias do Vale do Ribeira. O Ministério Público indeferiu o licenciamento alegando que o mesmo não poderia acontecer na esfera estadual e sim na federal, afinal a localização para construção da UHE é o trecho federal do rio Ribeira de Iguape, portanto, causando impactos interestaduais. A resolução (BRASIL, 1997) CONAMA no 237 determina que o licenciamento ambiental para projetos com impactos interestaduais, seja competência do Instituto Brasileiro de Meio Ambiente e Recursos Renováveis (IBAMA), o órgão federal responsável pelas análises. 
A segunda tentativa de obtenção de licenças ambientais ocorreu em 1997, quando a CBA protocolou documentos no IBAMA, e houve o indeferimento em 2003, desta vez, pelas insuficiências no Estudo de Impacto Ambiental (EIA).

\section{A terceira tentativa}

A terceira tentativa para obter licenciamento foi iniciada em 2004, com a apresentação de um novo Estudo de Impacto Ambiental/Relatório de Impacto Ambiental - EIA/RIMA.

A Área de Influência Direta (AID) e à Área de Influência Indireta (All) do mais recente projeto UHE Tijuco Alto são apresentadas a seguir.

Área de Influência Direta (AID) são áreas sujeitas aos impactos
diretos da implantação e operação do empreendimento [...]
Área de Influência Indireta (AII) é uma área real ou
potencialmente ameaçada pelos impactos indiretos da
implantação e operação do empreendimento, abrangendo o
ecossistema (biótico e não biótico) e o sistema sócioeconômico
que podem ser impactados por alterações ocorridas na Área de
Influência Indireta (CBA \& CNEC, 2005c: 34 - 35).

Por solicitação do IBAMA, o novo EIA/Rima está dimensionando os impactos ambientais cumulativos e sinérgicos do projeto UHE Tijuco Alto e dos projetos hidrelétricos de Itaóca, Funil e Batatal (integram a Bacia Hidrográfica do Rio Ribeira de Iguape). Segundo Crusco $^{5}$ (PARANÁ ON LINE, 2005) o IBAMA quer o impacto em Tijuco Alto e nas três localidades, apesar de não haver o interesse da CBA nas outras. Entretanto, a iminência de Tijuco Alto e o inventário aprovado pela Agência Nacional de Energia Elétrica - que apresenta na área de abrangência regional mais três barramentos existentes -, ocasionam ansiedade junto aos remanescentes quilombolas e configura cenário de impactos psicossociais (IBAMA, 2008: 17 - 18). A Figura 1 indica a Área de Influência Direta (AID) do atual projeto UHE Tijuco Alto.

\footnotetext{
${ }^{5}$ Ronaldo Luís Crusco é Coordenador Técnico Geral da Equipe Técnica CNEC responsável pelo projeto UHE Tijuco Alto.
} 
Figura 1. Localização da área de interesse nos Estados de SP e PR

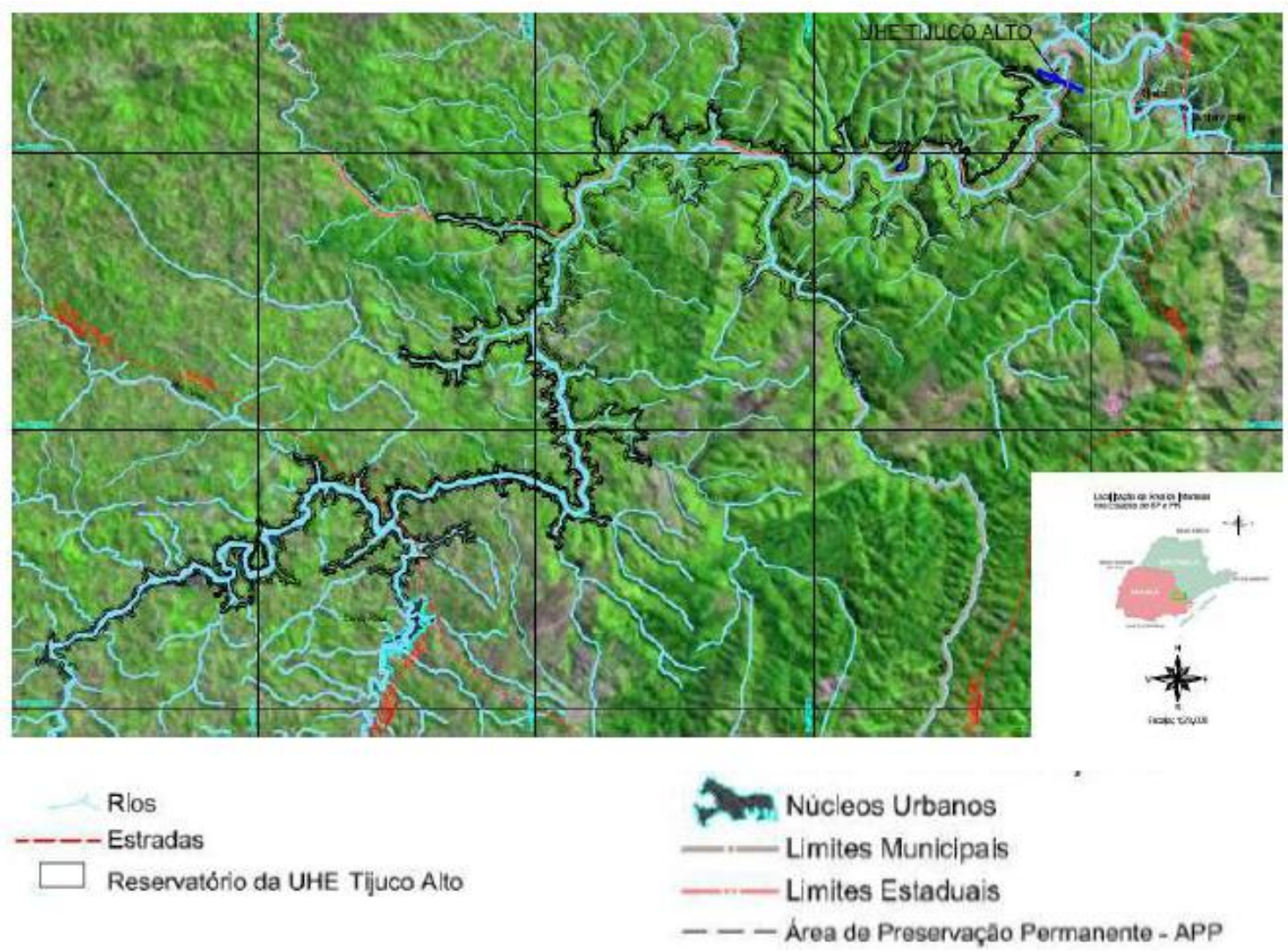

Fonte: CBA \& CNEC (2005c).

O novo projeto UHE Tijuco Alto é apresentado pela CBA \& CNEC com barragem de 120 metros de altura, potência instalada entre $120 \mathrm{MW}$ e $150 \mathrm{MW}$, e na AID estão as cidades de Adrianópolis/PR, Cerro Azul/PR, Doutor Ulysses/PR, Itapirapuã Paulista/SP, Ribeira/SP. O novo reservatório (CBA \& CNEC (2005c) apresenta comprimento de $71.5 \mathrm{~km}$ da barragem até o rio Bomba, no município de Cerro Azul/PR. A tabela 2 detalha a extensão do possível reservatório para cada um dos municípios inclusos na AID do projeto UHE Tijuco Alto. 
Tabela 2. Relação dos municípios que pertencem à AID e fazem parte dos estudos de sócioeconomia.

\begin{tabular}{|c|c|c|c|c|c|c|}
\hline Estado & Município & $\begin{array}{c}\text { Área } \\
\text { alagada } \\
(\text { ha) }\end{array}$ & $\begin{array}{c}\text { Reservatório } \\
(\%)\end{array}$ & $\begin{array}{c}\text { Território } \\
\text { municipal } \\
\text { alagado (\%) }\end{array}$ & $\begin{array}{c}\text { Área alagada } \\
\text { por Estado (ha) }\end{array}$ & $\begin{array}{c}\text { Total do } \\
\text { reservatório (\%) }\end{array}$ \\
\hline \multirow{2}{*}{$\begin{array}{c}\text { São } \\
\text { Paulo }\end{array}$} & Ribeira & 935,74 & 18 & 2,79 & \multirow{2}{*}{$1.442,70$} & 28 \\
\cline { 2 - 5 } & Itapirapuã & 506,96 & 10 & 1,24 & \multirow{2}{*}{$3.737,30$} & \multirow{2}{*}{72} \\
\hline \multirow{2}{*}{ Paraná } & Adrianópolis & 995,83 & 19 & 0,69 & \\
\cline { 2 - 6 } & Cerro Azul & $1.856,20$ & 36 & 1,38 & & \\
\cline { 2 - 6 } & Dr Ulysses & 885,27 & 17 & 1,13 & & \\
\hline
\end{tabular}

Fonte: UHE Tijuco Alto (2005c). (ha) = hectare.

A CBA \& CNEC (2005a: 62 - 63) estimam que a quantidade de famílias no meio urbano afetadas pelo empreendimento pode ser representada por 113 famílias, 398 pessoas e 88 imóveis, e a população rural perfaz o universo de 585 famílias, 2085 pessoas e 308 imóveis rurais.

Ainda que a CBA apresente no mais recente projeto UHE Tijuco Alto as preocupações com a população urbana e a rural, o tema passivo social não deixará de integrar a história deste projeto hidrelétrico. Segundo o Boletim Informativo do Empreendimento UHE Tijuco Alto (CNEC, 2007) foram identificadas 31 famílias não proprietárias deslocadas (pelo processo de apropriação de propriedades inicial) que farão parte do processo de seleção para o reassentamento. Entretanto, segundo o estudo de Jeronymo, Bermann e Guerra (2012) o passivo social já existente - decorrente das apropriações de propriedades quando o projeto foi apresentado para a região do Vale do Ribeira (em 1988), e os seus reflexos (deslocamentos de não proprietários de terras para o município que convier e a crise na economia das comunidades rurais) - não será solucionado.

A tentativa de visibilizar as famílias sem propriedade de terras e deslocadas sem indenização não responde pelo passivo já produzido e vivenciado e, da mesma forma, é questionável a existência de apenas "31" famílias representando a totalidade das famílias não proprietárias deslocadas (Jeronymo, Bermann, Guerra, 2012: 139).

O projeto UHE Tijuco Alto é questionado com relação aos passivos ambientais decorrentes das atividades de mineração do chumbo, mas também 
é interrogado quando o tema é a inundação das cavernas. Segundo Crusco (O Estado de São Paulo, 2005) não há risco de contaminação pelo chumbo porque a represa não atingirá as antigas áreas de mineração, e o reservatório somente inundará duas pequenas cavidades. As considerações de Camargo são contrapostas as afirmações de Crusco. Para Camargo ${ }^{6}$ (O Estado de São Paulo, 2005) a área identificada como AID de Tijuco Alto contém sítios arqueológicos, comunidades quilombolas e a Mata Atlântica, e o rio Ribeira de Iguape represado poderá elevar o teor de metais pesados presentes no solo, no leito do rio e intensificar os impactos na biodiversidade regional.

O Rima (CBA \& CNEC, 2005) aponta que o reservatório inundará duas grutas que representam o equivalente a $4 \%$ do patrimônio espeleológico regional. Entretanto, a SBE - Sociedade Brasileira de Espeleologia ${ }^{7}$ (2007), encaminhou parecer geoespeleológico referente ao EIA/Rima Tijuco Alto. Inicialmente, a SBE (2007) aponta que o EIA/Rima tem em sua composição dados imprecisos que podem acabar em dano ambiental e informações contraditórias. Segundo a SBE (2007) o EIA/Rima constata que a partir da avaliação do potencial espeleológico é possível analisar as implicações do enchimento do reservatório sobre a perda do patrimônio espeleológico e a própria estanqueidade do reservatório. Para tanto, o EIA/Rima propõe-se programas ambientais que possam monitorar/controlar as referidas implicações (SBE, 2007). Porém, para o parecer geoespeleológico da SBE (2007) não se encontram programas ambientais no EIA/Rima e, neste sentido, não se garante o monitoramento/controle proposto.

Quanto aos resíduos da mineração do chumbo, o parecer da SBE (2007) constata que EIA/Rima confirma o abatimento de $50.000 \mathrm{~m} 3$ de rejeitos, porém não aponta os mecanismos adotados para a impermeabilização do solo que abrigou as atividades da mineradora, logo, quando o tema é a contaminação do solo e do lençol freático, a conclusão é que as soluções não foram apresentadas.

A seção seguinte apresenta o levantamento de dados empíricos desenvolvido na AID do projeto UHE Tijuco Alto. São informações que

\footnotetext{
${ }_{7}^{6}$ Elci Camargo é Coordenadora Jurídica da Fundação SOS Mata Attântica.

${ }^{7}$ Instituição sem fins lucrativos, dedicada ao estudo e a preservação das cavernas brasileiras.
} 
contrastam com a quantidade de infraestrutura física (pontes, passarelas e pinguelas) identificada no EIA/Rima.

\section{Detecção das infraestruturas viárias (pontes, passarelas e pinguelas) inclusas na AID}

As atividades antrópicas, infraestruturas sociais e econômicas, estradas, comunidades, formas de vida animal e vegetal, incluídas na designada AID e, portanto, envolvidas pelo projeto hidrelétrico, devem integrar o EIA. Entretanto, a identificação das infraestruturas e as formas de vida não necessariamente estão integradas no EIA. O levantamento das informações empíricas foi desenvolvido pelo grupo de trabalho organizado pelo Dr Sevá ${ }^{8}$. As informações foram levantadas a partir da contribuição e do apoio logístico (transporte de automóvel) da Associação dos Trabalhadores da Agricultura Familiar (ASTRAF), Cerro Azul, PR, e do Centro de Estudos, Defesa e Educação Ambiental (CEDEA), Curitiba/PR. O percurso pela AID - pelas margens do Rio Ribeira de lguape, entre as cidades de Cerro Azul, PR, e Adrianópolis, PR - foi feito de automóvel. Além disso, neste percurso, foram registradas infraestruturas físicas (com imagens fotográficas e anotações em cadernos de campo) construídas sobre os rios afluentes do rio Ribeira de Iguape, respeitando o trecho do rio identificado para a ação.

Foram colhidas imagens nas Comunidades Rurais do Quarteirão dos Órfãos, Mato Preto, Bom Sucesso, Rocha, Tigre, Barra do rio Ponta Grossa, Ribeirão do Canha, Barra do rio do Carmo que contrastam com os dados apresentados pelo EIA. São infraestruturas viárias (pontes de madeira e alvenaria) construídas pelo poder público ou pelas comunidades rurais para a locomoção de pedestres, veículos e mercadorias, porém, elas estão excluídas do EIA/Rima.

\footnotetext{
${ }^{8}$ O grupo de trabalho foi organizado pelo Dr Arsênio Osvaldo Sevá Filho (Instituto de Filosofia e Ciências Humanas da Universidade Estadual de Campinas - UNICAMP) para levantar informações empíricas na AID do projeto UHE Tijuco Alto. O resultado deste trabalho é o parecer: Sevá, Rick e Minello (2007). Este parecer é um instrumento que oferece informação técnica para entidades e cidadãos engajados na campanha pela preservação do Vale do Ribeira e pela valorização das comunidades locais.
} 
O EIA do projeto UHE Tijuco Alto aponta a submersão das seguintes infraestruturas viárias.

\begin{abstract}
12,5 km, a partir da rodovia PR-092 até o remanso do reservatório, foz do rio Bomba, (municípios de Doutor Ulysses e Cerro Azul); neste trecho será inundada uma ponte sobre o rio Turvo [...] Trecho de 2,8 km da rodovia PR-092 a ser inundada, nos municípios de Cerro Azul e Doutor Ulysses, incluindo a ponte sobre o rio Ribeira [...] $38 \mathrm{~km}$ de estrada que liga a sede municipal de Cerro Azul à sede de Adrianópolis, sendo o primeiro trecho entre Cerro Azul e o bairro de Mato Preto $(15,5 \mathrm{~km})$, atingindo uma ponte sobre o rio Mato Preto; e o segundo entre o bairro do Rocha e o eixo da barragem (22,5 $\mathrm{km}$ ), com uma ponte sobre o rio do Rocha (CBA \& CNEC, 2005a: 74).
\end{abstract}

As informações contidas no EIA contrastam com os dados obtidos durante a coleta de dados. O levantamento de informações empíricas identificou 9 pontes de alvenaria, 3 pontes de madeira, 1 passarela, 1 pinguela. O percurso integral dos rios inclusos na AID, possivelmente, representará a identificação de um quantitativo maior de infraestrutura viária quando comparada com aquela disponibilizada no EIA e neste trabalho. As informações colhidas ao longo da pesquisa de campo são apresentadas a seguir.

Atravessando a ponte de alvenaria, entre as cidades de Cerro Azul/PR e Dr. Ulysses/PR, sentido Dr. Ulysses/PR, na Comunidade Barra do Tigre, existem dois afluentes do rio Ribeira de Iguape. O primeiro é o rio Tigre e a ponte de madeira, e o rio Turvo e a ponte de alvenaria. As duas infraestruturas não foram registradas, porém, são consideradas para fins de contabilização.

As figuras a seguir apresentam as infraestruturas viárias - pontes, passarelas e pinguelas - invisibilizadas pelo projeto UHE Tijuco Alto. 


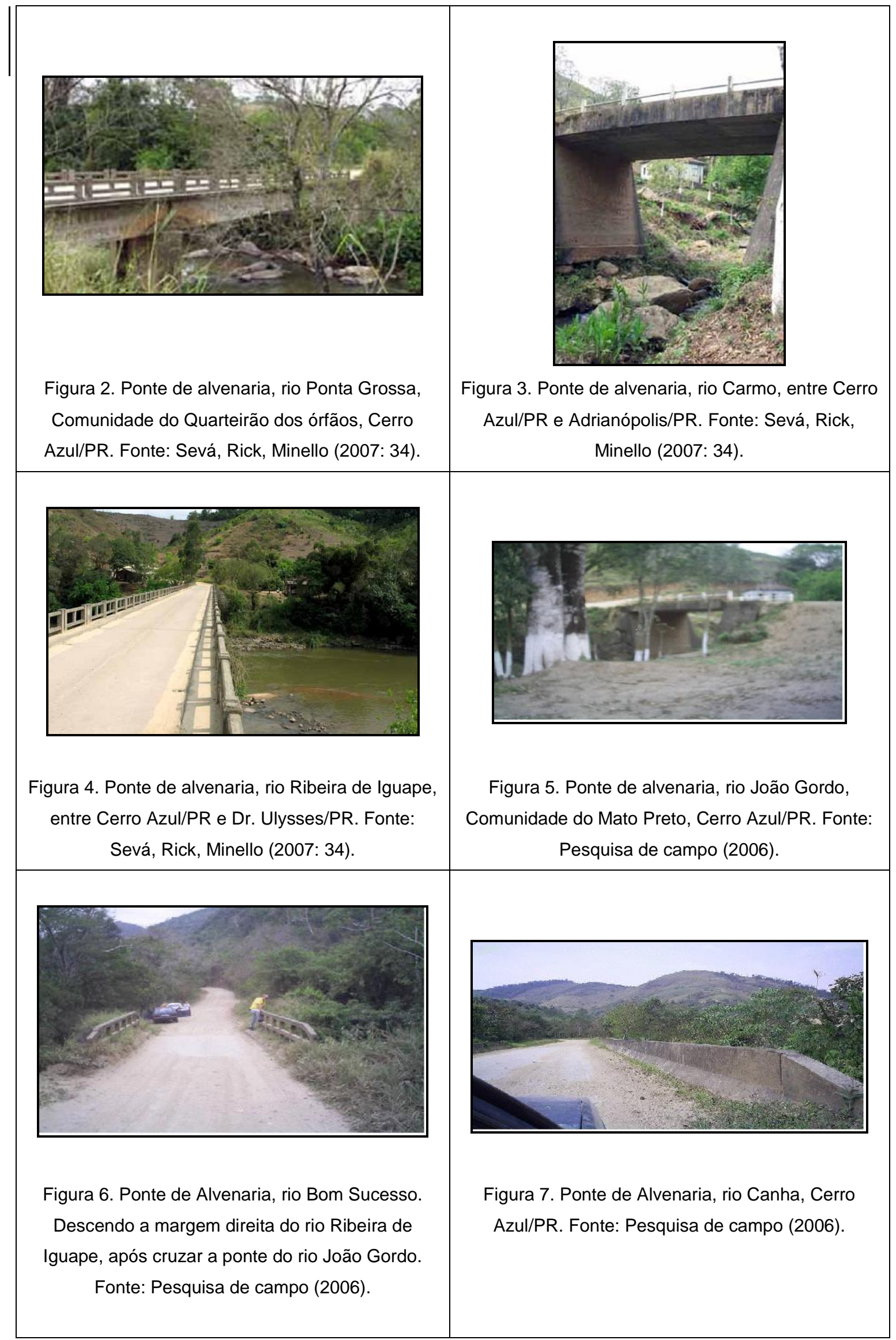




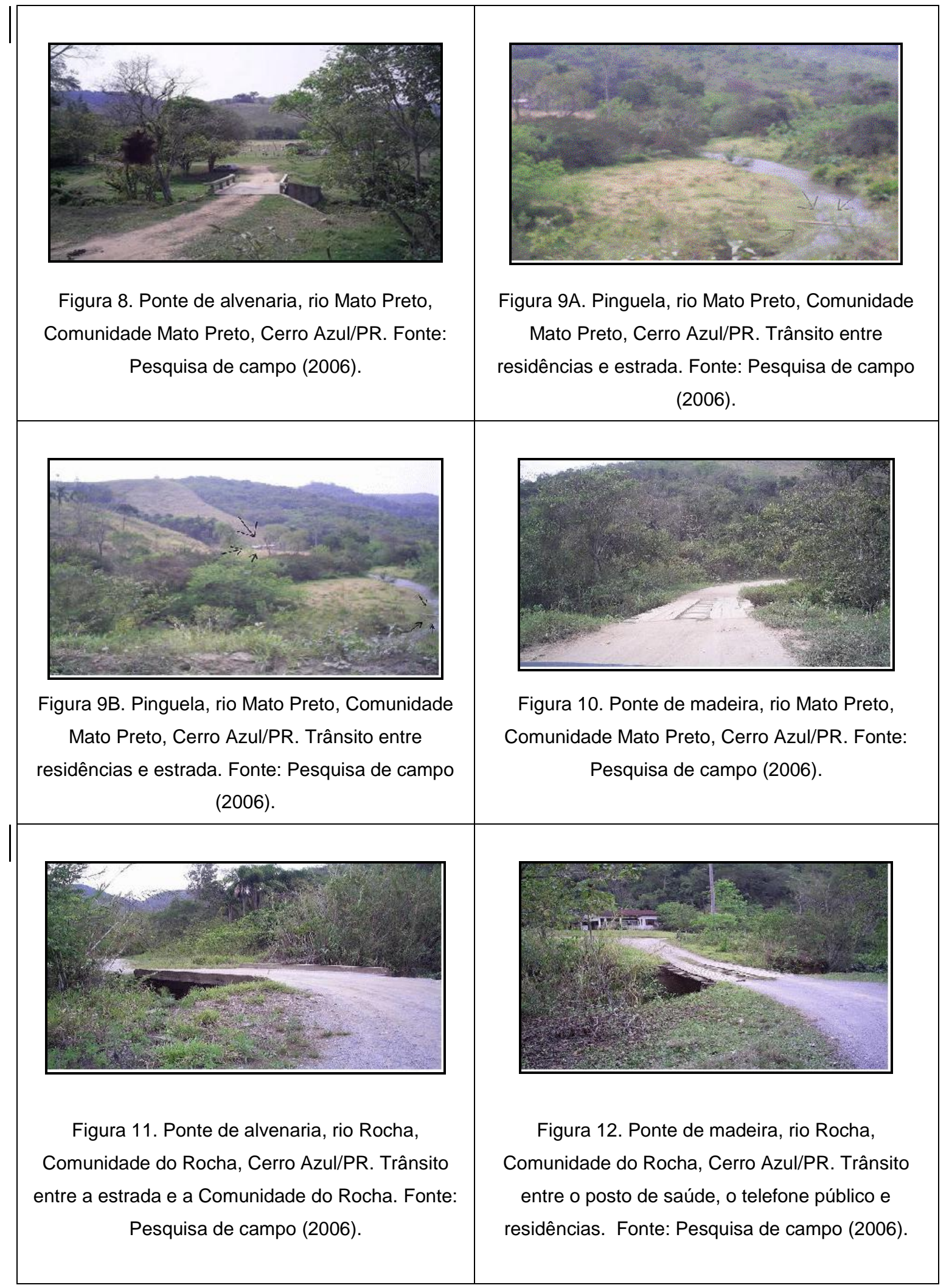




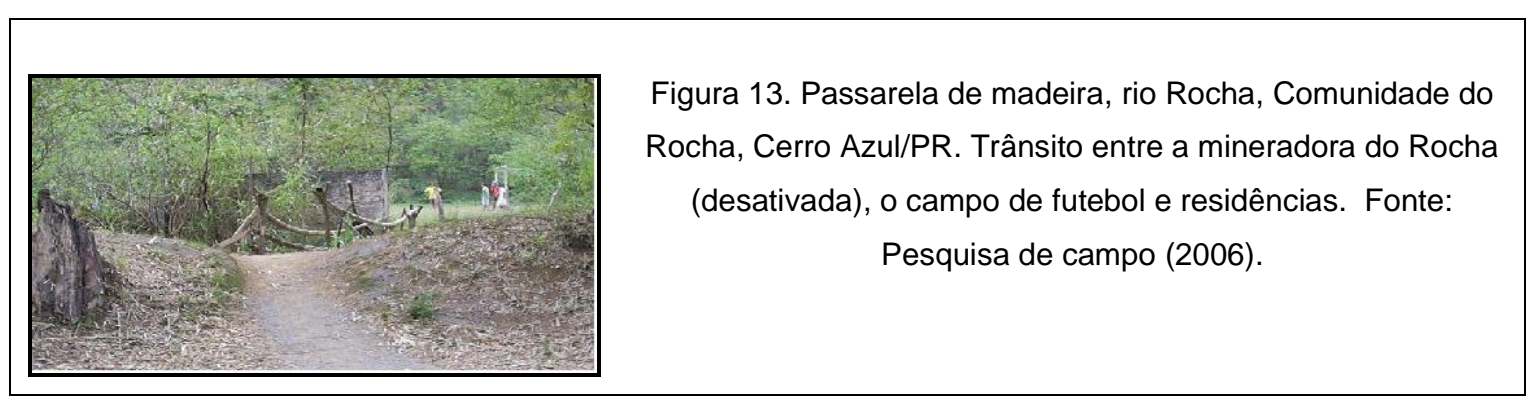

\section{Considerações finais}

A reduzida disponibilidade de técnicos capacitados para analisar pedidos de licenciamento ambiental, de modo geral, em regime de urgência, e a insuficiente infraestrutura dos órgãos responsáveis pelos licenciamentos são fatores que contribuem para aumentar o tempo para análises dos EIA. A apresentação de EIA com lacunas e incompletos é outro fator tributário do aumento do tempo para análises dos EIAs. A instituição responsável pela elaboração do documento inconsistente, o qual demandará dos órgãos ambientais prorrogação do tempo para avaliação, na verdade, está contribuindo para atrasar parecer oficial e, por extensão, obstruindo análises futuras.

As lacunas debilitam a qualidade do EIA e são indicadores que refletem a necessária análise aprofundada e criteriosa do estudo. Por conseguinte, a partir do EIA incompleto, é possível questionar lisura e a capacidade das empresas (consultoras e empreiteiras) responsáveis pela elaboração do EIA e, da mesma forma, questionar quem utiliza o documento inconsistente como instrumento para deferir licenças ambientais. Isto significa dizer que a função dos órgãos ambientais e do licenciamento ambiental não deve ser desprezada, pelo contrário, necessita prestígio, um processo contínuo de aprimoramento e, dada a diversidade dos elementos que correspondentes à elaboração do EIA, 0 corpo técnico que o avaliará necessita composição interdisciplinar. A diferença entre o que foi anunciado pelo EIA do projeto UHE Tijuco Alto e o identificado durante a pesquisa de campo é substancial.

A presença das infraestruturas viárias invisibilizadas do EIA não deve ser interpretada somente como uma falha na contabilização das mesmas, 
afinal, elas são utilizadas correntemente por pedestres, para o transporte de passageiros e mercadorias, e podem ser identificadas através do contato prévio com os seus usuários. A invisibilização das infraestruturas viárias do EIA permitirá ao agente econômico a isenção da responsabilidade em compensar ou substituir o que o documento não incluiu. $A$ isenção desonerará o agente econômico deste ressarcimento e onerará toda uma região com o impacto da subtração da infraestrutura.

A invisibilização não está restrita, exclusivamente, aos interesses de contenção de custo do agente econômico. A subtração das infraestruturas do EIA é um dos procedimentos que desqualifica o licenciamento ambiental. A sua não detecção induz a invisibilização da legislação ambiental e a desconstrução da Política Nacional de Meio Ambiente (PNMA). Neste sentido, a naturalização do agente econômico atuando, construindo e modificando os espaços conforme os próprios objetivos representam a invisibilização e a desqualificação da legislação ambiental.

O projeto UHE de Tijuco Alto apresenta como propósito 0 desenvolvimento regional, a geração de empregos, a dinamização econômica da região. Mediante a invisibilização das infraestruturas físicas é pertinente a seguinte indagação: quais são as vias para acessar o desenvolvimento regional através da subtração de infraestruturas?

\section{Referências}

ABAL - ASSOCIAÇÃO BRASILEIRA DO ALUMÍNIO. O Alumínio: alumínio primário. Disponível em: <http://www.abal.org.br/aluminio/producao _alupri.asp>. Acesso em: 10 abr. 2011.

ANEEL - AGÊNCIA NACIONAL DE ENERGIA ELÉTRICA. Banco de Informações da Geração (a). Agentes de Geração: Companhia Brasileira de Alumínio. Disponível em:<http://www.aneel.gov.br/aplicacoes/AgenteGeracao/

UsinasAgente.asp?fase=3\&empresa=1266:Companhia Brasileira de Alumínio $>$. Acesso em: 12 abr. 2011.

ANEEL - AGÊNCIA NACIONAL DE ENERGIA ELÉTRICA. Banco de Informações da Geração (b). Usinas e Centrais Geradoras. Disponível em: <http://www.aneel.gov.br/aplicacoes/capacidadebrasil/UsinaListaSelecao.asp>. Acesso em: 12 abr. 2011. 
BANCO MUNDIAL. Licenciamento ambiental de empreendimentos hidrelétricos no Brasil: uma contribuição para o debate. Brasília, 2008. Disponível em: $<$ http://www.maternatura.org.br/hidreletricas/biblioteca docs/Brazil licenciamen to_SintesePortugueseMarch2008.pdf>. Acesso em: 28 mar. 2011.

BRASIL. Agência Nacional de Energia Elétrica. Decreto n॰23, 10 de setembro de 1996. Regulamenta a produção de energia elétrica por produtor independente, e dá outras providências. Diário Oficial da República Federativa do Brasil, Poder Executivo, Brasília, DF, 11 set. 1996, seção 1, p. 17.917.

BRASIL. Congresso Nacional. Lei no 6.938, 31 de agosto de 1981. Dispõe sobre a Política Nacional do Meio Ambiente, seus fins e mecanismos de formulação e aplicação, e dá outras providências. Diário Oficial da República Federativa do Brasil, Poder Executivo, Brasília, DF, 31 ago. 1981.

BRASIL. Congresso Nacional. Lei no 6.803, 2 de julho de 1980. Dispõe sobre as diretrizes básicas para o zoneamento industrial nas áreas críticas de poluição e dá outras providencias. Diário Oficial da República Federativa do Brasil, Poder Executivo, Brasília, DF, 2 de jul. 1980.

BRASIL. Constituição (1988). Art no 23, 5 de outubro de 1988. É competência comum da União, dos Estados, do Distrito Federal e dos Municípios. Lex: legislação federal. Brasília, DF, 5 out. 1988.

BRASIL. Ministério de Meio Ambiente. Conselho Nacional de Meio Ambiente. Resolução no 1, 23 de janeiro de 1986. Define as situações e estabelece os requisitos e condições para desenvolvimento de Estudo de Impacto Ambiental - EIA e respectivo Relatório de Impacto Ambiental - RIMA. Diário Oficial da República Federativa do Brasil, Poder Executivo, Brasília, DF, 17 de fev. 1986.

BRASIL. Ministério de Meio Ambiente. Conselho Nacional de Meio Ambiente. Resolução oㅡ 237, 19 de dezembro de 1997. Dispõe sobre os procedimentos e critérios utilizados no licenciamento ambiental e no exercício da competência, bem como as atividades e empreendimentos sujeitos ao licenciamento ambiental. Diário Oficial da República Federativa do Brasil, Poder Executivo, Brasília, DF, 22 dez. 1997.

BRASIL. Ministério do Meio Ambiente. Secretaria de Mudanças Climáticas e Qualidade Ambiental. Departamento de Licenciamento e Avaliação. Manifestação sobre o estudo elaborado pelo Banco Mundial. Brasília, $2008 . \quad$ Disponível em: <http://www.abce.org.br/downloads/AVALIA\%C3\%87\%C3\%830_DO_RELAT\% C3\%93RIO_FINAL_LICENCIAMENTO_Volney_Zanardi_J.pdf >. Acesso em: 20 mar. 2011.

CBA - COMPANHIA BRASILEIRA DE ALUMÍNIO (a). Quem somos. Disponível em: <www.cba-brasileiro-aluminio.com.br/pt/quem.php>. Acesso em: 20 mar. 2011. 
CBA - COMPANHIA BRASILEIRA DE ALMÍNIO (b). Usinas: Localidades. Disponível em: <http://www.cia-brasileira-aluminio.com.br/pt/usinas.php>. Acesso em: 12 abr. 2011.

CBA - COMPANHIA BRASILEIRA DE ALUMÍNIO \& CNEC - CONSÓRCIO NACIONAL DE ENGENHEIROS CONSULTORES S.A (a). Identificação, caracterização e avaliação de impactos ambientais. In: Estudo de Impacto Ambiental da Usina Hidrelétrica de Energia Tijuco Alto. São Paulo: CBA \& CNEC, 2005. Capítulo 14, 74 p.

CBA - COMPANHIA BRASILEIRA DE ALUMÍNIO \& CNEC - CONSÓRCIO NACIONAL DE ENGENHEIROS CONSULTORES S.A (b). Metodologia geral para estudos de impactos ambientais. In: Estudo de Impacto Ambiental da Usina Hidrelétrica de Energia Tijuco Alto. São Paulo: CBA \& CNEC, 2005. Capítulo 2, 14 p.

CBA - COMPANHIA BRASILEIRA DE ALUMÍNIO \& CNEC - CONSÓRCIO NACIONAL DE ENGENHEIROS CONSULTORES S.A (c). Relatório de Impacto Ambiental (RIMA) da Usina Hidrelétrica de Energia Tijuco Alto. São Paulo: CBA \& CNEC, 2005.

CNEC - COMPANHIA NACIONAL DE ENGENHEIROS CONSULTORES. O Tijuco. Boletim Informativo do Empreendimento UHE Tijuco Alto. Ano III, $n$ 6, abr. 2007.

CONSÓRCIO EMPRESARIAL SALTO DO PILÃO. O Grupo: quem somos. Disponível em: <http://www.usinasaltopilao.com.br/>. Acesso em: 12 abr. 2011.

ENERCAN - Energia Campos novos. Empresas acionistas da Campos Novos Energia. Disponível em: <http://www.enercan.com.br/site/interno.

php?it=0\&conteudo=empresa\&sub=2>. Acesso em: 12. abr. 2011.

GODOY, Paulo. O Estado contra o presidente do IBAMA. Newslatter Diária Canal Energia. Rio de Janeiro, 15 jul. 2009. Disponível em: $<$ www.canalenergia.com.br>. Acesso em: 19 jul. 2009.

IBAMA - INSTITUTO BRASILEIRO DE MEIO AMBIENTE E RECURSOS RENOVÁVEIS. Parecer técnico sobre a viabilidade ambiental do empreendimento UHE Tijuco Alto - processo $n^{\circ}$ 02001.1172-2004-58. Brasília, 2008. Disponível em: < http://www.socioambiental.org/banco_imagens/pdfs/pareceribamatijucoalto.pdf >. Acesso em: 1.10.2012.

ISA - INSTITUTO SÓCIOAMBIENTAL. Municípios do Vale do Ribeira recebem diploma de patrimônio natural da humanidade. São Paulo, 2001. Disponível em: <http://www.socioambiental.org/nsa/detalhe?id=451>. Acesso: 20. jul. 2011.

JERONYMO, Alexandre Cosme José; BERMANN, Célio; GUERRA, Sinclair Mallet - Guy. Deslocamentos, itinerários e destinos de populações atingidas por barragens: UHE Tijuco Alto, SP - PR. Desenvolvimento e meio ambiente, n 25, p. 133 - 152, jan./jun. 2012. 
LEROY, Jean Pierre. Prefácio. In.: BERMANN, C. Energia no Brasil: para quê? Para quem? Crise e alternativas para um país sustentável. São Paulo: Ed. Livraria da Física e Federação dos Órgãos para Assistência Social e Educacional, 2001. p. 7 - 9.

LIMA, Luís Henrique. MAGRINI, Alessandra. The Brazilian Audit Tribunal's role in improving the federal environmental licensing process. Environmental Impact Assessment Review, v. 30, issue 2, p. 108 - 115, feb. 2010.

VEIGA, Lilian Elabras; POMBO, Felipe Ramalho. O processo de licenciamento ambiental e o setor energético. In: XII CONGRESSO BRASILEIRO DE ENERGIA - Desafios do setor energético - XII., 2008, Rio de Janeiro. Anais... Rio de Janeiro: Instituto Alberto Luiz Coimbra de Pós Graduação e Pesquisa em Engenharia, 2008, p. 1025 - 1039.

MACHADO, Paulo Afonso Leme. Regulamentação do estudo de impacto ambiental. In: SANTOS, Leinad Ayer de Oliveira; ANDRADE, Lúcia Mendonça Morato de Andrade (orgs.). As hidrelétricas do Xingu e seus povos. São Paulo: Comissão Pró-Índio, 1988. 77 - 81.

O ESTADO DE SÃO PAULO. Tijuco Alto reformula projeto. São Paulo, 2005. Acesso em: 2. mar. 2005.

PARANÁ ON LINE. Vale do Ribeira espera por Tijuco Alto. 22. mar. 2005. Curitiba, 2005. Disponível em: <http://www.paranaonline.com.br/editoria/cidades/news/115644/>. Acesso em: jun. 2012.

SEVÁ, Arsênio Osvaldo; RICK, Aline Tiana; MINELLO, Carla. Parecer independente sobre $o$ licenciamento e sobre os riscos do projeto. Campinas, 2006. Disponível em [http://www.fem.unicamp.br/ seva/parecerSEVA_HTA_28mar07.pdf]. Acesso em: 01 abr 2011.

SBE - SOCIEDADE BRASILEIRA DE ESPELEOLOGIA. Parecer geoespeleológico referente ao EIA-Rima UHE Tijuco Alto. Campinas, 2007. Disponível em: http://www.sbe.com.br/diversos/Parecer\%20Geoespeleol\%F3gico\%20EIA\%20 UHE\%20Tijuco\%20Alto.pdf >. Acesso em: set. 2012.

ZHOURI, Andréa; LASCHESFIKI, Klemens; PAIVA, Angela. Uma sociologia do licenciamento ambiental: o caso das hidrelétricas em Minas Gerais. In: ZHOURI, Andréa; LASCHESFIKI, Klemens; PEREIRA, Doralice Barros. (orgs.). A insustentável leveza da política ambiental: desenvolvimento e conflitos sociais. Belo Horizonte: Ed. Autêntica, 2005. 